\title{
Prevalence of Red Cell Blood Group Antigens Among Egyptian Population in Comparison with Other Ethnic Groups
}

\author{
RANDA M. ABOU EL-FETOUH, M.D.*; TAREK M.A. EL-GEMMEZI, E.F.B.T.M.**; \\ MERHAN A. FOUDA, M.D.* and FATEN M. MOFTAH, C.T.M-R.C.P.S. of Edinburgh*** \\ The Departments of Clinical Pathology (Blood Bank Unit), National Cancer Institute, Cairo University*, Red Cell Reference \\ Laboratory, National Blood Transfusion Services, Ministry of Health and Population** and International Blood Transfusion Services***, \\ Cairo, Egypt
}

\begin{abstract}
Background: Blood group antigens differ in their distribution among different ethnic populations, knowledge of the different blood antigen frequency in a population is important for safe blood transfusion, as cases of multi-transfused patients with multiple allo-antibodies, where antigen-negative blood should be provided.
\end{abstract}

Aim of the Work: Is to detect the prevalence of red cell blood group antigens among Egyptian population and compare it with other ethnic groups. This information can be used to establish the correlation between blood group genotype and phenotype, and to help managing cases of alloimmunization in multiply transfused patients.

Methodology: A total number of 3219 regular blood donors in NBTC and the blood bank of the National Cancer Institute, Cairo University, were subjected to extended Rh system phenotyping (D, C, E, c and e), and to phenotyping for other blood group systems. Colum Agglutination Technique was used to test the red cells of the blood donors.

Results: Our study showed that in the Rh system, the $\mathrm{D}+(84 \%), \mathrm{e}+(97.4 \%), \mathrm{C}+(67.5 \%)$ prevalence was close to Caucasians. The $\mathrm{K}$ antigen $(8.23 \%)$ was also almost close to Caucasian, while the $\mathrm{k}$ antigen $(99 \%)$ was equal to other ethnic population. The S and s antigens $(56.77 \%, 86.1 \%$ respectively) were almost the same as that of Caucasian and Indian population. Duffy blood group was different as Fya (26.66\%) and $\mathrm{Fyb}(48.87 \%)$ antigens results were unique to our studied population. The Lea $(26.26 \%)$ antigen was almost the same as both Caucasians and African population. While the Jka $(83.88 \%)$ antigen was close to the Indians population, the $\mathrm{Jkb}(58.75 \%)$, the Leb $(46.49 \%)$ and the $\mathrm{N}(40.1 \%)$ antigens were unique to our studied group. The M antigen (78.99\%) result was almost the same as Caucasian and Asian population.

Conclusion: The distribution of the blood group antigens among different races shows different findings. Knowledge of the prevalence of different blood group antigens in any given population is helpful in managing cases of alloimmunization in multiply transfused patients.

Correspondence to: Dr. Randa M. Abou El-Fetouh, E-Mail: randafetouh@yahoo.com
Key Words: Red cell - Blood group antigens - Egyptians Ethnic groups - Prevalance.

\section{Introduction}

BLOOD group antigens are inherited macromolecules on the outer surface of the red blood cell, and some of these antigens are present on the cell surface of various tissues, as they are not red cell specific. They may be proteins, glycolipids and mostly glycoproteins e.g. the ABO system specificity is determined by the oligosaccharide sequence, while the MN, Kell, Duffy, Kidd, and Diego system specificities are determined by the amino acid sequence [1].

The International Society of Blood Transfusion (ISBT) identifies almost 344 red cell surface antigenic determinants classified according to the following: 36 blood group Systems consisting of one or more antigens controlled at a single gene locus, or by two or more very closely linked homologous genes with little or no observable recombination between them; Collections (200 series) consist of serologically, biochemically, or genetically related antigens, which do not fit the criteria required for system status; 700 Series or low incidence antigens with an incidence of less than $1 \%$ and cannot be included in a system or collection and 901 Series or high incidence antigens with an incidence of greater than $90 \%$ and can't be included in a system or collection [2] .

Knowledge of the prevalence of different blood group antigens in any given population is always helpful in managing cases of allo-immunization especially multi-transfused patients. Several studies compared the phenotype frequencies among different ethnic groups and populations, especially those 
important in blood transfusion and in transplantation. As blood transfusion can carry immediate or delayed immunological risks; the most common and most serious is the hemolytic transfusion reaction by antibody incompatibility. Multitransfused patients (who often require chronic blood transfusion) such as patients suffering from thalassemia, sickle cell anemia, patients on dialysis, cancer patients, etc., are more likely to develop antibodies against minor blood group antigens, thus, antigen negative blood is required for those patients who are already allo-immunized and sometimes with more than one antibody. Finding compatible units for such patients without having any knowledge of the prevalence of the implicated antigens in the local population is a laborious and time consuming process [3-5].

Absence of surface antigenic expression in any blood group systems is known as null phenotype; they are rare and found accidentally when this person is immunized either by transfusion or pregnancy [1]. Though the $\mathrm{D}$ antigen is the most potent immunogen in the Rh system, other antigens in this system are capable of sensitizing the immune system giving rise to clinically significant antibodies, as when transfusing compatible Rh D blood units but are incompatible for $\mathrm{C}, \mathrm{c}, \mathrm{E}$ or e antigens. Antibodies specific to the Rh system are the most frequent antibodies encountered in pre-transfusion testing, and are the main cause of hemolytic disease of fetus and newborn (HDFN), and hemolytic transfusion reactions (HTRs) and antigen-negative blood should be available whenever possible. The $\mathrm{c}$ antigen is clinically the most important $\mathrm{Rh}$ antigen after the D antigen, causing severe HDFN, whereas antibodies to the $\mathrm{C}, \mathrm{E}$, and rarely e antigen can cause mild (but not always) HDFN $[3,6]$.

Delayed hemolytic transfusion reactions can be caused by some blood group systems as the $\mathrm{Rh}$ system where Anti-D, Anti-c, Anti-C, and anti-e, which can cause severe hemolytic transfusion reaction with extra vascular hemolysis. The $\mathrm{K}$ antigen is the most immunogenic antigen after the antigens of the $\mathrm{ABO}$ and $\mathrm{Rh}$ blood group systems causing severe hemolytic transfusion reaction $[5,7]$ Other antigens are also capable of producing antibodies causing HTRs, HDFN or even decrease red cell life span [8]. Knowledge of the phenotypic frequency of these antigens is required both in managing and preventing the development of alloantibodies in multi-transfused patients.

One-third of all non- $\mathrm{Rh}$ allo-antibodies are mainly anti-K, so providing K-persons with Kblood units is essential [7,9-12]. The Kell system is the third potent system capable of initiating an immune response after $\mathrm{ABO}$ and $\mathrm{Rh}$ systems due to the strong immunogenic $\mathrm{K}$ antigen, which is a low frequency allele in all studied populations. Anti- $\mathrm{K}$ antibodies should be considered potentially clinically significant, in causing severe HDFN and HTRs requiring transfusion with antigen-negative blood whenever possible. Mainly anti-K antibodies are known to cause severe reactions in numerous occasions causing HDFN, due to immune destruction of RBCs with significant suppression of erythropoiesis resulting in severe anemia, which may be prolonged and without overt signs of hemolysis. $[3,13,14]$

The Kidd blood group system has two major antigens $\mathrm{Jka}$ and $\mathrm{Jkb}$, besides being antigenic; they are the major urea transporters on erythrocytes. Jk (a-b-) individuals have no clinical symptoms, but have their urine concentrating ability reduced by about one-third [15]. Anti-Jka and anti-Jkb can cause severe immediate HTRs and sometimes delayed HTRs.As their plasma level drop to low or undetectable levels, they are often not detected and rarely can cause severe HDFN [3].Duffy blood group antigens are glycoprotein in nature functioning as receptors for cytokines and malaria parasite, Plasmodium vivax. Antigens of the Duffy system, (Fya and Fyb antigens) are capable of producing antibodies causing immediate or delayed HTRs, although mild, but sometime could be fatal, and being responsible for varying degree of HDFN, ranging from mild to severe. The phenotype Fy (a-b-), found mainly in Africans, lacking the Duffy glycoprotein from their red cells, affecting the susceptibility to malarial infections, resulting in natural selection. This phenotype is less common in other ethnic groups $[\mathbf{1 6 , 3 , 2 , 5 ]}$. Duffy and Kidd blood group antigens may act as a minor histocompatibility antigen in renal allograft rejection [17]

The MNS system have four major glycoprotein antigens $\mathrm{M}, \mathrm{N}, \mathrm{S}$ and $\mathrm{s}$, functioning as receptors for cytokines and Plasmodium falciparum. Anti$\mathrm{S}$ and anti-s were found to be implicated in HTRs and causing severe and fatal HDFN $[\mathbf{3 , 1 8}]$.

The Lewis system antigens, Lea and Leb, are adsorbed from the plasma, as they are not intrinsic to erythrocytes. The Leb antigen in the gastric mucosal epithelium is the receptor for Helicobacter pylori, which is the major causative agent of gastric ulcers $[19,20]$. It is extremely rare for $\mathrm{Le}(\mathrm{a}+)$ or $\mathrm{Le}(\mathrm{b}+)$ red cells to cause HTR as specific naturally occurring antibodies are almost exclusively in the sera of Le(a-b-) individuals [3,9]. 
Different antigen phenotyping is essential in initiating a donor blood bank registering all known antigen phenotypes as it would be helpful for patients with rare phenotype, or multi-transfused patients with multiple antibodies [21,22]. Donor bank registration could be helpful in prophylactic prevention of alloimmunization in young or pregnant females, and patients expecting to have multitransfusion in life, as in cases of thalassemia, sickle cell disease and patients with refractory aplastic anemia $[23,24]$.

Racial and ethnic variation in different blood group antigens frequency in Africa, Asia, Europe, North and South America was reported by several authors [25-29].

\section{Material and Methods}

A total number of 3219 regular blood donors from April 2015 to December 2016 in NBTC and the blood bank of the National Cancer Institute were subjected to extended Rh system phenotyping (D, C, E, c and e), and to other blood group systems phenotyping. The donation included both sexes, with 4/1 male to female ratio, age ranging from 18 to 45 years. All donors were asked to fill in a questionnaire to determine their eligibility for blood donation. Those considered as eligible donors were physically examined by a physician prior to acceptance of donation. Specimens were collected, stored and handled according to the assay manufacturers' instructions. The study was approved by the Institutional Review Board of the National Cancer Institute (NCI), Cairo University.

The classical method used for testing the blood group antigens was hemagglutination; Colum Ag- glutination Technique using Mono-specific anti sera (Biorad Laboratories, Inc., Hercules, Califormia, USA) as this serological technique used to test the red cells of the blood donors being simple, inexpensive with appropriate specificity and sensitivity. For collection of specimen, a $3 \mathrm{ml}$ fresh, non-hemolysed EDTA blood sample was used for preparation of 5\% RBCs suspension to detect RBCs antigens. Quality Control was done using positive \& negative control specific for each Anti-serum, refereeing to standard operating procedures (SOPs) of preparation of controls for different immune-hematological reagents to ensure specificity of reagent and to avoid false positive and negative results. Red cell suspension was tested with the mono specific anti sera using Biorad (Biorad Laboratories, Inc., Hercules, Califormia, USA) column agglutination cards. Positive test results in case of red cell agglutination and negative test results in case of no agglutination of RBCs.

This study was approved by the Institutional Review board of the National Cancer Institute on 3 rd of March 2015 and the IRB approval number is 201001415020.2.

\section{Results}

A total number of 3219 regular blood donors in NBTC and the blood bank of the National Cancer Institute were subjected to extended $\mathrm{Rh}$ system phenotyping (D, C, E, c and e), and to phenotyping for other blood group systems.Our results are shown in Table $(1,2)$. The prevalence of phenotypes associated with the blood group antigens among our study group in comparison with other ethnic groups are shown in Tables $(3,4,5)$.

Table (1): Results of the study group showing the prevalence of Rh Phenotype.

\begin{tabular}{|c|c|c|c|c|c|c|c|}
\hline & Cases tested & $\begin{array}{c}\text { Prevalanceof } \\
\text { RBC antigens } \\
(\%)\end{array}$ & $\mathrm{D}$ & $\mathrm{C}$ & $\mathrm{E}$ & $\mathrm{c}$ & $\mathrm{e}$ \\
\hline $\mathrm{R} 2 \mathrm{r}$ & 283 & $8.79 \%$ & + & & + & + & + \\
\hline $\mathrm{R} 1 \mathrm{R} 1$ & 683 & $21.22 \%$ & + & + & - & - & + \\
\hline $\mathrm{R} 1 \mathrm{r}$ & 1125 & $34.95 \%$ & + & + & - & + & + \\
\hline $\mathrm{R}_{1} \mathrm{R}_{2}(\mathrm{Rzr})$ & 271 & $8.42 \%$ & + & + & + & + & + \\
\hline $\mathrm{R} 0 \mathrm{r}$ & 297 & $9.23 \%$ & + & - & - & + & + \\
\hline $\mathrm{R} 2 \mathrm{R} 2$ & 67 & $2.1 \%$ & + & - & + & + & -- \\
\hline $\mathrm{rr}$ & 446 & $13.86 \%$ & - & - & - & + & + \\
\hline r'r & 34 & $1.1 \%$ & - & + & - & + & + \\
\hline $\mathrm{r} " \mathrm{r}$ & 13 & $0.40 \%$ & - & - & + & + & + \\
\hline \multirow{2}{*}{ Total } & \multirow{2}{*}{3219} & Number & 2726 & 2113 & 634 & 2536 & 3152 \\
\hline & & $\%$ & 84.68 & 65.64 & 19.7 & 78.78 & 97.92 \\
\hline
\end{tabular}


Table (2): The prevalence of the different minor blood groups in the study group.

\begin{tabular}{|c|c|c|c|c|c|c|c|c|c|c|c|c|}
\hline & \multicolumn{2}{|c|}{ Kell } & \multicolumn{2}{|c|}{ Duffy } & \multicolumn{2}{|c|}{ Kidd } & \multicolumn{2}{|c|}{ Lewis } & \multicolumn{4}{|c|}{ MNSs } \\
\hline & $\mathrm{K}$ & $\mathrm{k}$ & Fya & Fyb & $\mathrm{JKa}$ & $\mathrm{JKb}$ & Lea & Leb & M & $\mathrm{N}$ & S & $\mathrm{s}$ \\
\hline Total tested samples & 3222 & 2200 & 2251 & 2204 & 2270 & 2240 & 2239 & 2205 & 2208 & 2200 & 2276 & 2203 \\
\hline Positive cases & 265 & 2172 & 600 & 1077 & 1904 & 1316 & 588 & 1025 & 1744 & 880 & 1292 & 1896 \\
\hline Positive cases $(\%)$ & 8.23 & 99 & 26.66 & 48.87 & 83.88 & 58.75 & 26.26 & 46.49 & 78.99 & 40.1 & 56.77 & 86.1 \\
\hline
\end{tabular}

Table (3): Comparison of the different minor blood groups in our study with other ethnic groups.

\begin{tabular}{lllllllllllll}
\hline & $\mathrm{K}$ & $\mathrm{k}$ & $\mathrm{Fya}$ & $\mathrm{Fyb}$ & $\mathrm{JKa}$ & $\mathrm{JKb}$ & $\mathrm{M}$ & $\mathrm{N}$ & $\mathrm{S}$ & $\mathrm{s}$ & Lea & Leb \\
\hline Egyptians (\%) & 8.23 & 99 & 26.66 & 48.87 & 83.88 & 58.75 & 78.99 & 40.1 & 56.77 & 86.1 & 26.26 & 46.49 \\
Caucasians (\%) & 9 & 98 & 66 & 83 & 77 & 74 & 78 & 72 & 55 & 89 & 22 & 72 \\
Black (\%) & 2 & 100 & 10 & 23 & 92 & 49 & 74 & 75 & 31 & 93.0 & 23 & 55 \\
Asians (\%) & Rare & 100 & 99 & 18.5 & 72 & 76 & 79.7 & 67.4 & 8.7 & 100 & - & - \\
Indians (\%) & 3.5 & 99.7 & 87.4 & 57.7 & 81.4 & 67.6 & 88.8 & 65.4 & 54.8 & 88.7 & - & - \\
\hline
\end{tabular}

Table (4): Comparison of the Rh phenotype between our study group and other ethnic groups.

\begin{tabular}{cccccccc}
\hline & Egyptians (\%) & Cote d'Ivoire (\%)§ & \multicolumn{1}{c}{ Indians (\%) Caucasians/ Whites (\%) } & Blacks (\%) & Iran (\%)* & Asians (\%) \\
\hline D & 84.68 & 92.93 & 93.4 & 85 & 92 & 90.2 & 99.0 \\
C & 65.64 & 21.97 & 84.8 & 68 & 27 & 75.9 & 93.0 \\
E & 19.7 & 13.82 & 17.9 & 29 & 22 & 29.5 & 39.0 \\
$\mathrm{c}$ & 78.78 & 99.85 & 52.8 & 80 & 98 & 73.9 & 47.0 \\
$\mathrm{e}$ & 97.92 & 99.85 & 98.3 & 98 & 98 & 97.9 & 96.0 \\
\hline
\end{tabular}

Please see references for the detailed data $9:[30] . \quad$ §: [31]. $\quad$ *: [32].

Table (5): Comparison between Rh phenotype (Weiner notation) prevalance between our study group and other ethnic groups.

\begin{tabular}{|c|c|c|c|c|c|}
\hline Rh-Phenotype & Egyptians (\%) & Whites [Caucasian] (\%) & Blacks (\%) & Asians (\%) & South Indians $(\%)^{*}$ \\
\hline $\mathrm{R} 1 \mathrm{R} 1$ & 21.22 & 18.5 & 2.0 & 51.8 & 40.87 \\
\hline $\mathrm{R} 2 \mathrm{R} 2$ & 2.1 & 2.3 & 0.2 & 4.4 & \\
\hline $\mathrm{R}_{1} \mathrm{R} 2\left(\mathrm{R}_{\mathrm{zr}}\right)$ & 8.42 & 0.2 & rare & 1.4 & 13.91 \\
\hline $\mathrm{R}_{1} \mathrm{r}$ & 34.95 & 34.9 & 21.0 & 8.5 & 23.48 \\
\hline $\mathrm{R} 2 \mathrm{r}$ & 8.79 & 11.8 & 18.6 & 2.5 & 4.35 \\
\hline $\mathrm{R}_{0} \mathrm{r}$ & 9.23 & 2.1 & 45.8 & 0.3 & 0.87 \\
\hline $\mathrm{rr}$ & 13.86 & 15.1 & 6.8 & 0.1 & 11.3 \\
\hline r'r & 1.1 & 0.8 & rare & 0.1 & - \\
\hline $\mathrm{r}^{\prime \prime} \mathrm{r}$ & 0.40 & 0.9 & rare & rare & - \\
\hline
\end{tabular}

Please see references for the detailed data $*:[33]$

\section{Discussion}

Knowledge about the frequency of red cells antigens phenotypes in our population can be useful in initiating a donor data bank for minimizing the risks of alloimmunization for multi-transfused patients as most transfusions are done based only on the $\mathrm{ABO}$ and $\mathrm{D}$ antigens with little or no data available for the frequency of other blood group antigens. Blood transfusion is used mainly to save life, but this is not without risk, as an immediate or delayed hemolytic transfusion reaction due to antigen incompatibility could occur. Knowing the frequency of the blood group antigens phenotype in our population is important in managing alloimmunization in multi-transfused patients, as finding compatible units without knowing the prevalence of the desired antigen in our population or in any ethnic population is a time and reagent consuming work $[3,4,28]$.

Studying the Rh phenotype it was found that $\mathrm{R} 1 \mathrm{r}$ was highest in value (34.95\%) which is equal to that of Caucasian, followed by $\mathrm{R} 1 \mathrm{R} 1$ with a result of $21.22 \%$ and rr with $13.86 \%$ both values are almost close to Caucasian population. $\mathrm{R}_{0} \mathrm{r}$ (9.23\%), R1R2 ( $\left.\mathrm{R}_{\mathrm{z}} \mathrm{r}\right)(8.42 \%), \mathrm{R} 2 \mathrm{r}(8.79 \%)$, and r"r $(0.4 \%)$ showed a percentage unique to our 
studied population. The D,C, c, e antigens in our study showed a percentage of $(84.68 \%, 65.64 \%$, $78.78 \%$ and $97.92 \%$ respectively) which is almost the same as that in Caucasians except for the $\mathrm{E}$ antigen (19.7\%) giving a value which was close to Indians and black population than to Caucasians. The Kell phenotype showed a different result for both antigens were the $\mathrm{K}$ antigen $(8.23 \%)$ showed a value almost close to Caucasian than to other ethnic population, while the $\mathrm{k}$ antigen $(99 \%)$ was equal to other ethnic population. The Duffy blood group was different as Fya (26.66\%) and Fyb $(48.87 \%)$ antigens results were unique to our studied population. As for the kidd blood group antigen the Jka $(83.88 \%)$ result was close to the Indians population, while the $\mathrm{Jkb}(58.75 \%)$ was unique to our studied group. The $\mathrm{M}$ antigen (78.99\%) result was almost the same Caucasian and Asian population, while the $\mathrm{N}$ antigen (40.1\%) showed a unique percentage to our studied group.

The $\mathrm{S}$ and s antigens $(56.77 \%, 86.1 \%$ respectively) in our studied group were almost the same as that of Caucasian and Indian population. The Lewis blood group showed difference in the expression of both the antigens as Lea $(26.26 \%)$ was almost the same as both Caucasians and African population, while the Leb (46.49\%) was unique to our studied group [25,29]

\section{Conclusion :}

The distribution of the blood group antigens among different races shows different findings. This has clinical significance in transfusion medicine and in hemolytic disease of fetus and newborn (HDFN), as it is essential to provide antigennegative blood to patients with medical conditions, who often require regular blood transfusion and who may have developed multiple antibodies. This study has provided us with donor database of regular repeat voluntary blood donors with known antigenic profile. Although our studied blood donor group are considered a small group compared to our country population, but still, it gives an estimate of the frequencies of minor blood group antigens. It is recommended that extended phenotypic status for $\mathrm{Rh}$ and Kell systems be determined routinely along with $\mathrm{ABO}$ and $\mathrm{Rh}(\mathrm{D})$ typing before the first transfusion as a preventive measure reducing potential allo-immunization, especially in multitransfused patients.

\section{References}

1- DANIELS G.: Functions of red cell surface proteins. Vox Sanguinis., 93: 331-340, doi: 10.111 1/j. 1423-0410.2007. 00970.x, 2007.
2- REID M.E.: The ISBT 700 series of low-incidence and 901 series of high incidence blood group antigens. Immunohematology, 27 (4): 131-5, 2011.

3- DANIELS G. and BROMILOW I.: Essential Guide to Blood Groups, 1 st ed.; Blackwell publishing, Oxford., 16, 2007.

4- CONTRERAS M.: Cellular antigens as immunogens in blood transfusion and pregnancy: Immunogenetic aspects of blood transfusion and bone marrow transplantation. Proceedings of the European School of Transfusion Medicine, 10-15, 1998.

5- REID M.E. and LOMAS-FRANCIS C.: The Blood Group Antigen Facts Book. 2nd ed. 2, New York: Elsevier Academic Press, 3-6, 2004.

6- ESTEP T.N., PEDERSEN R.A., MILLER T.J. and STUPAR K.R.: Characterisation of erythrocte quality dring the refrigerated storage of whole blood containing di (2-ethyl-hexyl) phthalate. Blood, 64 (6): 1270-6, 1984.

7- DANIELS G.; Human Blood Groups, Blackwell Science, Oxford, UK, $\quad$ edition., 195-275, 2002

8- POOLE J. and DANIELS G.: Blood group antibodies and their significance in transfusion medicine. Transfusion Medicine Reviews, 21 (1): 58-71, 2007.

9- BRECHER M.E.: Technical Manual, American Association of Blood Banks, Bethesda, Md, USA, $15 \mathrm{t}^{\mathrm{h}}$ edition, 341342, 2005.

10- Harmening D.M.: Modern Blood Banking and Transfusion Practices, FA Davis Company, Philadelphia, PA, USA, $5 \mathrm{t}^{\mathrm{h}}$ edition, 162-192, 2005.

11- CLEGHORN T.E.: MNSs gene frequencies in English blood donors, Nature, 187 (4738), 701, 1960.

12- RACE R.R and SANGER R.: Blood Groups in Man, Blackwell Scientific Publications, Oxford, UK, 4 th edition., 1975.

13- VAUGHAN J.I., et al.: Inhibition of erythroid progenitor cells by anti-Kell antibodies in fetal alloimmune anemia. N. Engl. J. Med., 338, 798-803, 1998.

14- VAUGHAN J.I., WARWICK R., LETSKY E., NICOLINI U., RODECK C.H. and FISK N.M.: Erythropoietic suppression in fetal anemia because of Kell alloimmunization. Am. J. Obstet. Gynecol. Jul., 171(1): 247-52, 1994.

15- SANDS J.M., et al.: Urinary concentrating ability in patients with $\mathrm{Jk}(\mathrm{ab}-)$ blood type who lack carrier-mediated urea transport. J. Am. Soc. Nephrol., 2: 1689-1696, 1992.

16- KWIATKOWSKI D.P.: How Malaria has affected the Human Genome and what Human Genetics can teach us about Malaria. The different geographic distributions of $\alpha$ thalassemia, GPD deficiency, ovalocytosis, and the Duffy-negative blood group are further examples of the general principle that different populations have evolved different genetic variants to protect against malaria. American Journal of Human Genetics., 77 (2): 171-192, doi:10.1086/432519, 2005.

17- LERUT E., et al.: Duffy and Kidd blood group antigens: minor histocompatibility antigens involved in renal allograft rejection? Transfusion, 47: 28-40, 2007

18- DEAN L.: Blood Groups and Red Cell Antigens [Internet] Bethesda (M.D.): National Center for Biotechnology 
Information (US)., http://www.ncbi.nih.gov/books/ NBK2269/, 2005.

19- BOREN T., et al.: Attachment of Helicobacter pylori to human gastric epithelium mediated by blood group antigens. Science, 262: 1892-1895, 1993.

20- BOREN T., et al.: Helicobacter pylori: molecular basis for host recognition and bacterial adherence [review]. Trends Microbiol., 2: 221-228, 1994.

21- DANIELS G.: The molecular genetics of blood group polymorphism. Human Genetics, 126: 729, 2009.

22- FLORES M.A., VISENTAINER J.E., GUELSIN G.A., FRACASSO A.S., DE MELO F.C., HASHIMOTO M.N. and SELL A.M.: Rh, Kell,Duffy, Kidd and Diego blood group system polymorphism in Brazilian Japanese descendants. Transfusion and Apheresis Science., 50: 123, 2014.

23- DIEDRICH B., ANDERSSON J., SALLANDER S. and SHANWELL A.K.: Fy(a), and Jk(a) phenotyping o donor RBCs on microplates. Transfusion, 41: 1263, 2001.

24- LAMBA D.S., KAUR R. and BASU S.: Clinically significant minor blood group antigens amongst North Indian donor population. Advances in Hematology, Vol. 2013, Article ID 215454: 5 pages, doi:10.1155/2013/ 215454, 2013.

25- SISTONEN P., KOISTINEN, J. and ADEN A.O.: Distribution of blood groups in the East African Somali population. Human Heredity, 37: 300, 1987.

26- HARMENING D.: Modern Blood Banking and Transfusion Practices, 2nd ed., FA Davis, Philadelphia, PA, 78, 1989.
27- MAKROO R.N., BHATIA A., GUPTA R. and PHILLIP J.: Prevalence of Rh, Duffy, Kell, Kidd \&MNSs blood group antigens in the Indian blood donor population. Indian J. Med. Res., 137 (3): 521-526, 2013.

28- REID M.E. and LOMAS-FRANCIS C.: Blood Group Antigens and Antibodies: A Guide to Clinical Relevance and Technical Tips. SBB Books, New York, NY., 2007

29- REID M.E., LOMAS-FRANCIS C. and OLSSON M.L.: The Blood Group Antigen Facts Book, ${ }^{\text {rodn. Elsevier }}$ Academic Press, London, UK., 2012.

30- SIRANSY BOGUI L., DEMBELE B., SEKONGO Y., ABISSE S., KONATÉ S. and SOMBOM: Phenotypic Profile of Rh and Kell Blood Group Systems among Blood Donors in Cote d'Ivoire, West Africa. Journal of Blood Transfusion Volume 2014, Article ID 309817: 4 pages http://dx.doi.org/10.1155/2014/309817, 2014.

31- KERAMATI M.R., SHAKIBAEI H., KHEIYYAMI M.I., et al.: "Blood group antigens frequencies in the northeast of Iran,” Transfusion and Apheresis Science, Vol. 45 (2): 133-136, 2011.

32- LIN-CHU M., BROADBERRY R.E. and CHAN F.J.: The distribution of blood group antigens and alloantibodies among Chinese in Taiwan. Transfusion, 28: 350-2, 1988.

33- THAKRAL B., SALUJA K., SHARMA R.R. and MARWAHA N.: Phenotype frequencies of blood group systems (Rh, Kell, Kidd, Duffy, MNS, P, Lewis, and Lutheran) in North Indian blood donors. Transfusion and Apheresis Science, 43 (1): 17-22, 2010.

\section{مقارنة بين الفصائل المختلفة بكرات الدم الحمراء

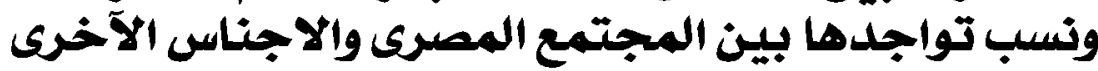

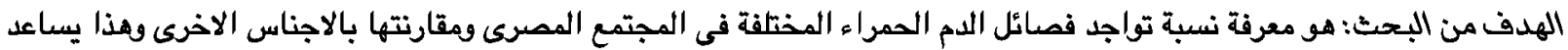

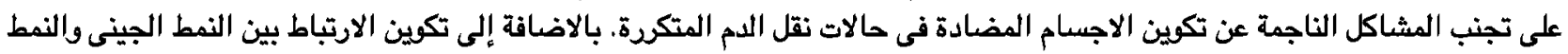

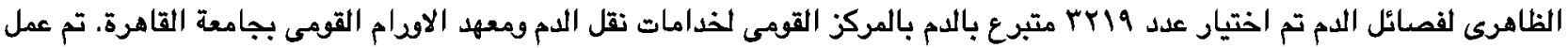

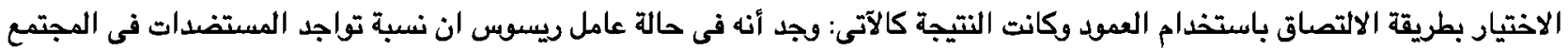

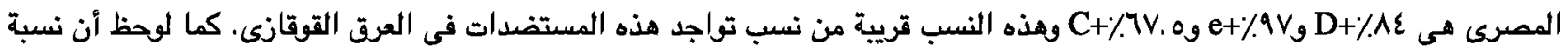

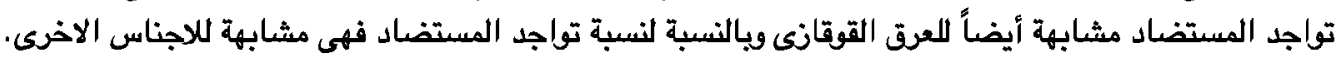

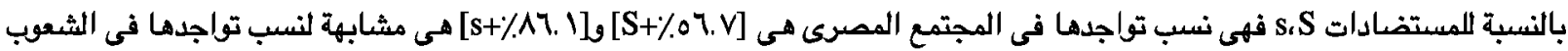

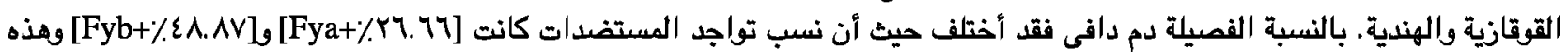

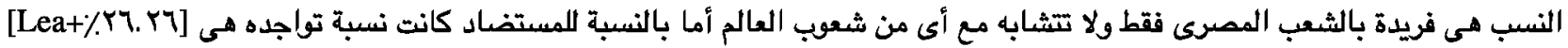

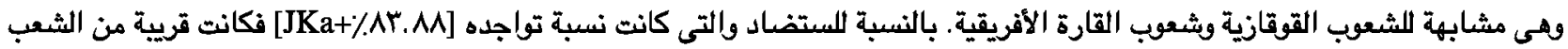

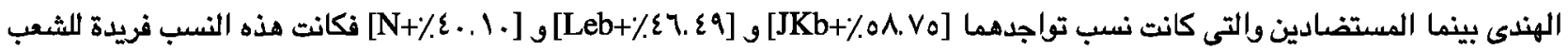

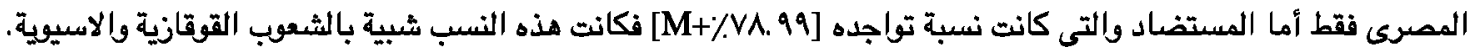

